Effects of Natural Aging on the Tensile Properties of Water-Quenched U-6\% Nb Alloy

A. J. Sunwoo, D. S. Hiromoto

January 5, 2004

Journal of Nuclear Materials 
This document was prepared as an account of work sponsored by an agency of the United States Government. Neither the United States Government nor the University of California nor any of their employees, makes any warranty, express or implied, or assumes any legal liability or responsibility for the accuracy, completeness, or usefulness of any information, apparatus, product, or process disclosed, or represents that its use would not infringe privately owned rights. Reference herein to any specific commercial product, process, or service by trade name, trademark, manufacturer, or otherwise, does not necessarily constitute or imply its endorsement, recommendation, or favoring by the United States Government or the University of California. The views and opinions of authors expressed herein do not necessarily state or reflect those of the United States Government or the University of California, and shall not be used for advertising or product endorsement purposes. 


\title{
Effects of Natural Aging on the Tensile Properties of Water-Quenched U-6\% Nb Alloy
}

\author{
A.J. Sunwoo and D.S. Hiromoto \\ Lawrence Livermore National Laboratory, 7000 East Avenue, \\ P. O. Box 808 L-140, Livermore, CA 94551-9900, USA
}

\begin{abstract}
Uranium-6 wt-\% niobium (U-6\% Nb) alloy has been in use for many years in the waterquenched (WQ) condition. The purpose of this work was to determine the effect of natural aging on tensile properties of the WQ U-6\% Nb alloy. The materials studied were hemispherical shells after 15 and 20 years in storage. The alloy was successfully tested in the original curved configuration, using the specially designed tensile test apparatus. Finite element analysis confirmed the validity of the test method. The results of the tensile tests clearly indicated that in the WQ condition, the material is changing and after 15 and 20 years, the yield strength exceeds the original maximum allowable specification. The fracture mode transitions from highly ductile, microvoid coalescence in new material to a mixed mode of shallow dimples and inclusion-induced voids in the naturally aged material.
\end{abstract}

\section{Introduction}

The wrought and heat treatment processing of uranium- $6 \mathrm{wt}-\%$ niobium (U-6\% $\mathrm{Nb}$ ) alloy has been optimized and the alloy has been in use for many years [1-4]. The solution heat treatment of the water quenching (WQ) operation leaves the alloy in the metastable $\alpha$ " phase state and retains the $\mathrm{Nb}$ atoms in solid solution. Supersaturated $\mathrm{Nb}$ atoms are strongly driven by thermodynamics to precipitate and reach a more stable state. However, the room temperature diffusion kinetics are too slow to allow precipitation to occur. It is speculated that the spinodal decomposition occurs during cooling to form $\mathrm{Nb}$-rich and $\mathrm{Nb}$-lean clusters, allowing random segregation to preferred lattice sites [5].

To stabilize and to prevent movement of the formed parts caused by the shape memory effects of the U-6\% $\mathrm{Nb}$ alloy, artificial aging (AA) has been added to the final heat treatment. An additional benefit of AA is the increased yield strength of the alloy through precipitation of supersaturated $\mathrm{Nb}$ clusters. The presence of a relatively coherent $\mathrm{Nb}$ second phase is more effective in impeding the movement of interphase and intervariant interfaces of the twinned structure $[5,6]$.

Some applications do not require high yield strength of the alloy. As a result, the formed parts went into service in the WQ state. Many aluminum alloys [7] have a strong tendency to naturally age after the solution heat treatment and water quench operation. Given the same heat treatment condition, the WQ U-6\% Nb alloy will change with time 
[8]. The purpose of this work was to determine the effect on tensile properties of natural aging in the WQ U-6\% Nb alloy. The materials studied were hemispherical shells after 15 and 20 years in storage.

\section{Experimental}

The pedigree of the shells was originally certified as $\mathrm{U}-6 \% \mathrm{Nb}$ alloy. Since it is difficult to be exactly at $6 \%$, the material specification allows the $\mathrm{Nb}$ content to vary from 5.2 to $6.5 \%$ [9], while still keeping the phase as $\alpha^{\prime \prime}[10,11]$. To determine the variation in $\mathrm{Nb}$ concentration and carbon impurity in the shell, samples were taken every $10^{\circ}$ starting from the pole region to the equator. The analysis technique employed was inductively coupled plasma atomic emission spectroscopy.

Optical metallography samples were also taken to characterize the microstructure from near the pole, the $45^{\circ}$ region, and the equator. A standard polishing technique was used. To display grain boundaries and inclusions, the samples were electroetched in a 1:1 orthophosphoric acid and water solution. To examine the twinned structure, the electrolytic etchant was a mixture of $10 \%$ perchloric acid and $90 \%$ glacial acetic acid. Both etching processes used a stainless steel cathode. The voltage was 18 to $20 \mathrm{VDC}$, with a duration of 2 to 3 minutes. The images were taken using "Nomarski" differentialinterference-contrast (DIC) illumination. Depending on the microstructure of interest, the etching solution and the microscopy technique can be varied.

Tensile data in the original curved configuration of the shell were obtained using a specially fabricated test apparatus. The test samples were extracted from three locations (pole, $45^{\circ}$, and equator) in three orientations (tangential, $45^{\circ}$, and radial) and machined into miniature tensile specimens. The specimen size and the tensile test apparatus are shown in Fig. 1. All tensile specimens were pulled to failure at a constant crosshead travel of $1.27 \mathrm{~mm} / \mathrm{min}$ (an initial strain rate of $4.2 \times 10^{-3} / \mathrm{s}$ ) at $25^{\circ} \mathrm{C}$. At least two specimens were tested for each condition. Elongation and cross-sectional area changes were measured using an optical comparator. Thickness measurements were determined with a point micrometer. The fracture surfaces were examined using a scanning electron microscope (SEM).

\section{Results and Discussion}

\section{Chemistry}

The results of the sample chemical analysis are summarized in Table 1. The average bulk $\mathrm{Nb}$ content for this particular part is about 5.7\%, which is slightly lower than the values reported by Ludwig [2]. Nonetheless, the $\mathrm{Nb}$ values are within the material specification requirements. The carbon content is sufficiently below the maximum allowable limit, except for the Sample 9, where the bulk sample could have contained numerous carbide inclusions. Energy dispersive spectroscopy of an inclusion displayed strong $\mathrm{Nb}$ and $\mathrm{C}$ peaks, suggesting the $\mathrm{Nb}$ contained carbide inclusion. The $\mathrm{Nb}$ carbide inclusions tend to have a squarer and a rod-like appearance [12]. 
It is well known that the carbide inclusions in the material reduce ductility $[12,13]$. The inclusions reside in the alloy incoherently within the matrix or at grain boundaries. Under tensile loading, the first interfaces to debond are between the inclusion and matrix or within the inclusions. The large inclusions break up easily since they are fragmented during wrought processing. Figure 2 shows the gage length area of the tensile sample strained to $25 \%$. Some of the inclusions may have etched out, but the localized damage sites are clearly seen. The U-6\% Nb alloy tensile specimen starts to neck beyond $25 \%$ and ultimately fails around 35\% strain. The negative effect of the carbon/carbide inclusions in the alloy was not seen in the tensile data. Figure 3 plots the tensile strength and elongation values as a function of $\mathrm{C}$ content. To remove the curvature, Ludwig [2] deformed the tensile specimens flat prior to testing, which yielded lower elongation values. Prior deformation on the material had a greater adverse effect than the high $\mathrm{C}$ content.

\section{Microstructure}

The wrought processing of the alloy was performed at the $\gamma$-phase temperature of $800^{\circ} \mathrm{C}$ or higher. During the last forming operation, the parts were tool quenched to minimize the distortion caused by the shape memory effect of the alloy. The relatively slow cooling rate allows diffusional decomposition to occur from the $\gamma_{1}$-phase to a two-phase equilibrium structure of unalloyed $\alpha-\mathrm{U}$ and $\mathrm{Nb}$-rich $\gamma$-phase, jeopardizing the benefits of $\mathrm{Nb}$ alloying addition to $\mathrm{U}$ [14]. The formed parts were solution heat treated at $800^{\circ} \mathrm{C}$ for 2 hours, followed by a water quench operation. The parts are checked for roundness requirements. The parts went into service in the WQ condition and returned after 15 and 20 years.

The overall characteristics of the microstructure should not change with time since there was no thermomechanical work applied to the parts over their lifetime. Figure 4 displays the microstructural features of the wrought processed $\mathrm{U}-6 \% \mathrm{Nb}$ alloy. Rapid cooling from $800^{\circ} \mathrm{C}$ to $25^{\circ} \mathrm{C}$ transforms the $\gamma$-phase to the highly twinned $\alpha^{\prime \prime}$ phase within the $\gamma$ phase grains. The average grain size is about $70 \mu \mathrm{m}$. In Figure $4 \mathrm{~b}$, the $\alpha^{\prime \prime}$ twinned structure is accentuated. The preliminary TEM characterization of the WQ samples confirmed that the size of the twins was not constant. Some areas contained a finely twinned structure, while other areas had large twins and untwinned regions [15]. A more detailed TEM study by Field et al [16] found that the monoclinic distortion associated with the finely twinned lath or band structure of $\alpha$ " greatly decreases the shear of specific twinning systems, facilitating twinning deformation.

The TEM characterization by Hsiung [17] of the 15 year naturally aged samples revealed that the presence of the anti-phase domain boundaries (APBs) and the superlattice diffractions correspond to the ordered $\mathrm{U}_{3} \mathrm{Nb}$ phase. He also observed that the formation of APBs indicates the occurrence of an order-disorder transformation. The ordered solid solution has the same structure as that of the disordered solution, but it takes up a superlattice arrangement because of the periodic occupation of lattice sites by specific 
atom species. The systematic variations in the atomic positions result in different order domains separated by APBs across which the atoms have wrong immediate neighbors. The spinodal decomposition observed within naturally aged $\mathrm{U}-6 \% \mathrm{Nb}$ might be the early stage of an order-disorder transformation.

\section{Simulations of tensile test apparatus}

In order to validate the test method used to obtain the tensile data, computational finite element analysis (FEA) of the tensile testing of conventional un-curved and curved specimens was performed [18]. The model represents the sample accurately, but simplifies the boundary conditions. It removes the sliding surfaces, and replaces them with a zero velocity boundary condition. Also, it starts the model inside the clamps. Instead of modeling the clamps, it applies velocities to the ends of the sample. A schematic of the actual boundary conditions on the specimen is show in Fig. 5, along with the simplification used in the FEA model. The model of the straight specimen is similar, except there is no velocity constraint along the length of the model.

In addition, due to the geometry of the setup (see Fig. 1c), the force applied to the apparatus is different than the force applied to the sample. The data needs to be compensated for this difference. From the sum of moments about the pivot point on the axis of symmetry, the following formula is obtained:

$$
F_{\text {sample }}=F_{\text {apparatus }} \frac{r_{f_{-} \text {applied }}}{r_{\text {sample }}}=L F_{\text {apparatus }}
$$

The test data need to be multiplied by the lever $\operatorname{arm} L$, a ratio of the radius at which force is applied to the radius at which the sample is located. $L$ should be applied according to Eqn. 1. Table 2 shows the values of $L$ for each of the existing apparatus.

The results of the FEA are shown in Fig. 6. At first, the response of the curved sample differs from that of the straight sample, namely the equivalent plastic strain across the thin part of the curved sample is asymmetric. At high levels of strain, the two samples start to look increasingly similar, where the outside edge bows in to match the curved inside edge, making the sample look nearly symmetrical. From this, one might expect the two tests to show differences in the low-stress part of the stress-strain curve, and then converge at higher stress/strain.

The resulting stress-strain curves show even more similarities in Fig. 7. Due to the averaging nature of the experimental stress-strain measurements (only a single force and a single averaged displacement are measured), the asymmetries across the curved specimen become unimportant. The difference in stress-strain curves for the straight vs. the curved specimens is $<<1 \%$, and the difference between these two curves and the original experimental curve is $<5 \%$. However, there are potential sources of error in the FEA simulations, namely the exact position of the clip gauge used to measure strain, friction on apparatus pins, local deformation around sample clamps, specimen and 
apparatus tolerances, and lack of friction between the specimen and its supporting surface. Given that, based on the simulation results, the small degree of curvature in the specimen and apparatus does not produce significant differences in comparison to the conventional straight specimen tests.

\section{Tensile properties}

The results of the adjusted average tensile data of the WQ, naturally aged U-6\% Nb alloy are given in Table 3. The data from our testing is compared with historical data from BWXT, Y-12 [19]. The tensile property requirements were specified for the WQ condition. During manufacturing, to ensure that the formed parts experienced the proper cooling rate in the WQ operation, a series of coupons were heat-treated concurrently and subsequently tensile tested. If the coupon tensile property values met the material property requirements, then the heat-treated formed parts were machined to final shape. The historical data are from these coupon tests. The present data clearly indicate that the strength of the alloy has increased. In some locations, the yield strength exceeds the maximum allowable specification value. The UTS values are comparable to those of AA material [20].

It is evident that the strength of the WQ $\mathrm{U}-6 \% \mathrm{Nb}$ alloy has changed with time. An analytical electron microscopy study by Ludka [5] observed very fine, coherent, homogeneously distributed precipitates populating the $\alpha$ " matrix, inhibiting the mobility of twinning deformation. Clusters of supersaturated $\mathrm{Nb}$ may precipitate with time at low temperature to impede the migration of twin interfaces at low strains. These precipitates may correspond to the $\mathrm{Nb}$-rich phase observed by Hsiung [17]. The clusters of $\mathrm{Nb}$ atoms may be the precursor to $\gamma_{1,2}$ that is controlling the work hardening behavior of the naturally aged $\mathrm{U}-6 \% \mathrm{Nb}$ alloy. In other alloy systems [21], high yield strength is attributed to the population of extremely fine precipitates within the grains. The TEM characterization of WQ $\mathrm{U}-6 \% \mathrm{Nb}$ alloy by Jenkins and Edmonds [22] revealed that a transition occurs as the tensile strain increases from reversible deformation by the migration of transformation twins to irreversible deformation by slip leading to a high density of dislocations at intervariant boundaries and within the $\alpha$ " bands and by mechanical twinning.

\section{Fractography}

All specimens failed in shear. Figure 8 shows the fracture surfaces of a WQ, 20-year naturally aged $\mathrm{U}-6 \% \mathrm{Nb}$ alloy specimen. The appearance of the fracture surface does not exhibit exceedingly ductile fracture, as typically seen in other fractography of WQ only $\mathrm{U}-6 \%$ alloy. The fracture surface is free of large cavities formed by the inclusions and contains mostly fine, shallow dimples. These shallow dimples that are free of inclusions could be the cleaved twinned structures of $\alpha^{\prime \prime}$.

In comparison, Fig. 9 shows the fractography of the AA U-6\% $\mathrm{Nb}$ alloy specimen after 10 years in service [20]. The fracture surface revealed significantly different fracture 
behavior, displaying the highly ductile void coalescence of a cup and cone morphological failure [13]. There are noticeable differences in the reduction in area and the size of inclusion-induced voids.

\section{Conclusions}

The water-quenched, naturally aged parts of $\mathrm{U}-6 \% \mathrm{Nb}$ alloy were successfully tested in the original curved configuration, using the specially designed tensile test apparatus. Finite element analysis confirmed the validity to the test method.

The results of the tensile tests clearly indicate that in the water-quenched condition, the material is changing. After 15 and 20 years, the yield strength exceeds the original maximum allowable specification. The fracture mode transitions from highly ductile, microvoid coalescence in new material to a mixed mode of shallow dimples and inclusion-induced voids in the naturally aged material.

\section{Acknowledgment}

This work was performed under the auspices of the US Department of Energy by the University of California, Lawrence Livermore National Laboratory under contract W7405-Eng-48.

\section{References}

[1] R. J. Jackson and D. V. Miley, Trans. ASM, 61, 1968, 336.

[2] R. L. Ludwig, Y-2144-3, 1979.

[3] R. A. Vandermeer, J. C. Ogle, and W. G. Northcutt, Jr., Met. Trans. A, 12A, 1981, 733.

[4] Physical Metallurgy of Uranium Alloys, J. J. Burke et al., eds., Brook Hill, (1976) 189.

[5] G. M. Ludka, Y-2336-10, 1985.

[6] D. A. Carpenter, Y-2346, 1985.

[7] J. T. Staley, Mater. Sci. Tech., 3, 1987, 923.

[8] D. H. Wood, J. W. Dini, and H. R. Johnson, J. Nucl. Mater., 114, 1983, 199.

[9] BWXT, Y-12, Material Specification, 00-M-200.

[10] M. Anagnostidis, M. Columbie, and H. Monti, J. Nucl. Mater., 11, 1964, 67.

[11] K. Tangri and D. K. Chaudhuri, J. Nucl. Mater., 15, 1965, 278.

[12] D. E. Beck, H. L. Wigginton, and V. Hock, Y-2142-3, 1979.

[13] R. W. Hertzberg, Deformation and Fracture Mechanics of Engineering Materials, $3^{\text {rd }}$ ed., Wily \& Sons, NY, 1976.

[14] K. H. Ecklemeyer, A. D. Romig, and L. J. Weirick, Met. Trans. A, 12A. 1984, 1319. 
[15] J. S. Harper, Unpublished Internal report, 2002.

[16] R. D. Field, D. J. Thoma, P. S. Dunn, D.W. Brown, and C. M. Cady, Phil. Mag. 81, 2001, 1691.

[17] L. L. Hsiung, LLNL, UCRL-CONF-201143, 2003.

[18] C. L. Goerzen, Unpublished data, 2003.

[19] BWXT Y-12, Unpublished data, 2003.

[20] A. J. Sunwoo, Unpublished test data, 2003.

[21] A. Gysler, G. Lutjering, and V. Gerold, Acta Met., 22, 1974, 901.

[22] B. A. Jenkins and D. V. Edmonds, Mater. Sci. Forum, 56-58, 1990, 323. 
Table 1. Bulk hemical analyses of a WQ U-6\% Nb alloy formed part as a function of location.

\begin{tabular}{|l|l|l|l|l|l|l|l|l|l|l|l|}
\hline & Spec $^{1}$ & 1 & 2 & 3 & 4 & 5 & 6 & 7 & 8 & 9 & Ludwig $^{2}$ \\
\hline $\begin{array}{l}\mathrm{Nb} \\
(\mathrm{wt}-\%)\end{array}$ & $5.2-6.5$ & 5.8 & 5.9 & 5.7 & 5.5 & 5.8 & 5.7 & 5.6 & 5.8 & 5.7 & $5.8-6$ \\
\hline $\begin{array}{l}\mathrm{C} \\
(\mathrm{ppm})\end{array}$ & $\begin{array}{l}200 \\
\max \end{array}$ & 93 & 103 & 107 & 85 & 85 & 80 & 73 & 82 & 227 & $52-141$ \\
\hline
\end{tabular}

${ }^{1}$ Depleted uranium-6 wt\% niobium alloy material specifications [9].

${ }^{2}$ Ludwig [2].

Table 2: Apparatus lever arm correction factors.

\begin{tabular}{|c|c|}
\hline Test apparatus \# & L \\
\hline 1 & 0.907 \\
\hline 2 & 0.928 \\
\hline 3 & 0.941 \\
\hline
\end{tabular}

Table 3. Adjusted average tensile properties of WQ U-6\% $\mathrm{Nb}$ alloy formed parts that have been in storage for 15 and 20 years.

\begin{tabular}{|c|c|c|c|c|c|c|c|c|}
\hline \multirow{3}{*}{$\begin{array}{l}\text { Specimens } \\
\text { Specification }^{1} \\
\end{array}$} & \multicolumn{2}{|c|}{$\begin{array}{c}\text { Yield strength } \\
(\mathrm{MPa})\end{array}$} & \multicolumn{2}{|c|}{$\begin{array}{c}\text { UTS } \\
(\mathrm{MPa}) \\
\end{array}$} & \multicolumn{2}{|c|}{ Elongation $(\%)$} & \multicolumn{2}{|c|}{$\begin{array}{c}\text { Red in area } \\
(\%)\end{array}$} \\
\hline & \multicolumn{2}{|c|}{$100-200$} & \multicolumn{2}{|c|}{$700 \mathrm{~min}$} & \multicolumn{2}{|c|}{$25 \mathrm{~min}$} & \multicolumn{2}{|c|}{-} \\
\hline & Avg & StDev & Avg & StDev & Avg & StDev & Avg & StDev \\
\hline Historical data ${ }^{2}$ & 149 & 12 & 845 & 21 & 32 & 1 & - & - \\
\hline \multicolumn{9}{|l|}{$\mathrm{WQ}+15$ years } \\
\hline $\begin{array}{l}\text { Near Pole } \\
\text { tangential }\end{array}$ & 196 & 2 & 868 & 2 & 38 & 3 & 34 & $<<1$ \\
\hline $45^{\circ}$ radial & 216 & 18 & 870 & 14 & 37 & $<1$ & 33 & 1 \\
\hline $\begin{array}{l}\text { Equator } \\
\text { tangential }\end{array}$ & 211 & 4 & 898 & 4 & 36 & 3 & 32 & 3 \\
\hline Equator@45 & 208 & 1 & 884 & 2 & 38 & 1 & 35 & 6 \\
\hline Equator radial & 198 & 3 & 884 & 11 & 37 & $<<1$ & 37 & 2 \\
\hline Summary & 206 & 9 & 881 & 12 & 37 & 1 & 35 & 2 \\
\hline \multicolumn{9}{|l|}{$\mathrm{WQ}+20$ years } \\
\hline $\begin{array}{l}\text { Near Pole } \\
\text { tangential }\end{array}$ & 244 & 26 & 900 & 2 & 35 & 1 & 39 & 1 \\
\hline Near Pole@45 & 213 & 14 & 881 & 7 & 34 & 4 & 36 & 1 \\
\hline Near Pole radial & 228 & 46 & 896 & 2 & 35 & $<<1$ & 34 & 2 \\
\hline $45^{\circ}$ tangential & 243 & 4 & 923 & 6 & 34 & 2 & 34 & 1 \\
\hline $45^{\circ} @ 45^{\circ}$ & 244 & 11 & 936 & 24 & 36 & 2 & 32 & 2 \\
\hline $45^{\circ}$ raidal & 240 & 3 & 923 & 5 & 39 & 6 & 32 & 7 \\
\hline $\begin{array}{l}\text { Equator } \\
\text { tangential }\end{array}$ & 230 & - & 915 & 11 & 32 & 2 & 30 & 4 \\
\hline Equator@45 & 211 & 9 & 943 & 2 & 31 & 2 & 30 & 2 \\
\hline Equator raidal & 230 & 15 & 923 & 4 & 35 & 1 & 32 & $<<1$ \\
\hline Summary & 231 & 13 & 915 & 21 & 35 & 2 & 33 & 3 \\
\hline
\end{tabular}

${ }^{1}$ Depleted uranium-6 wt\% niobium alloy material specification [9].

${ }^{2}$ Historical data [19]. 
a
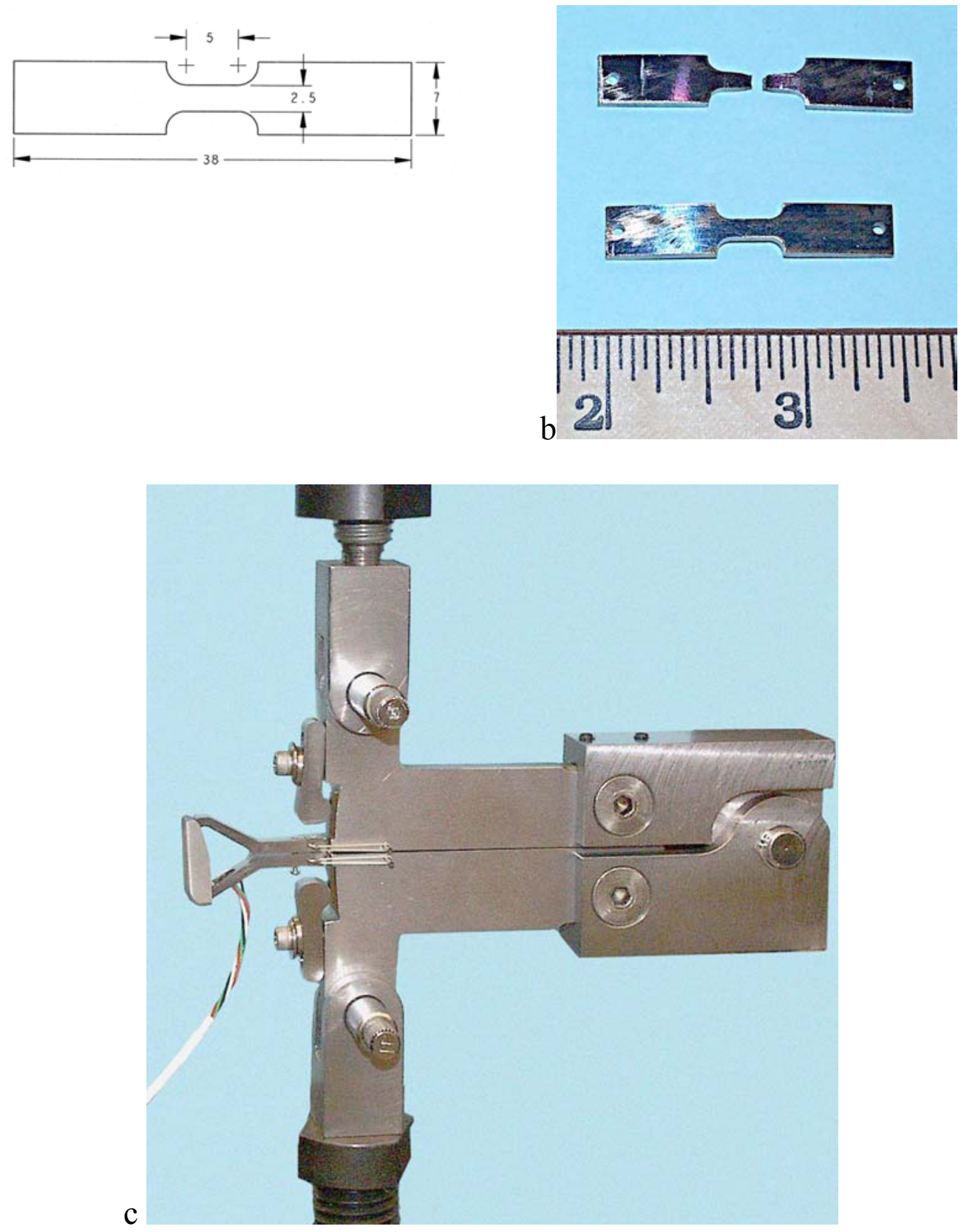

Figure 1. A schematic of the specimen illustrated in $\mathrm{mm}$ (a), the actual tensile specimens before and after broken shown in inches (b), and tensile test apparatus (c). 

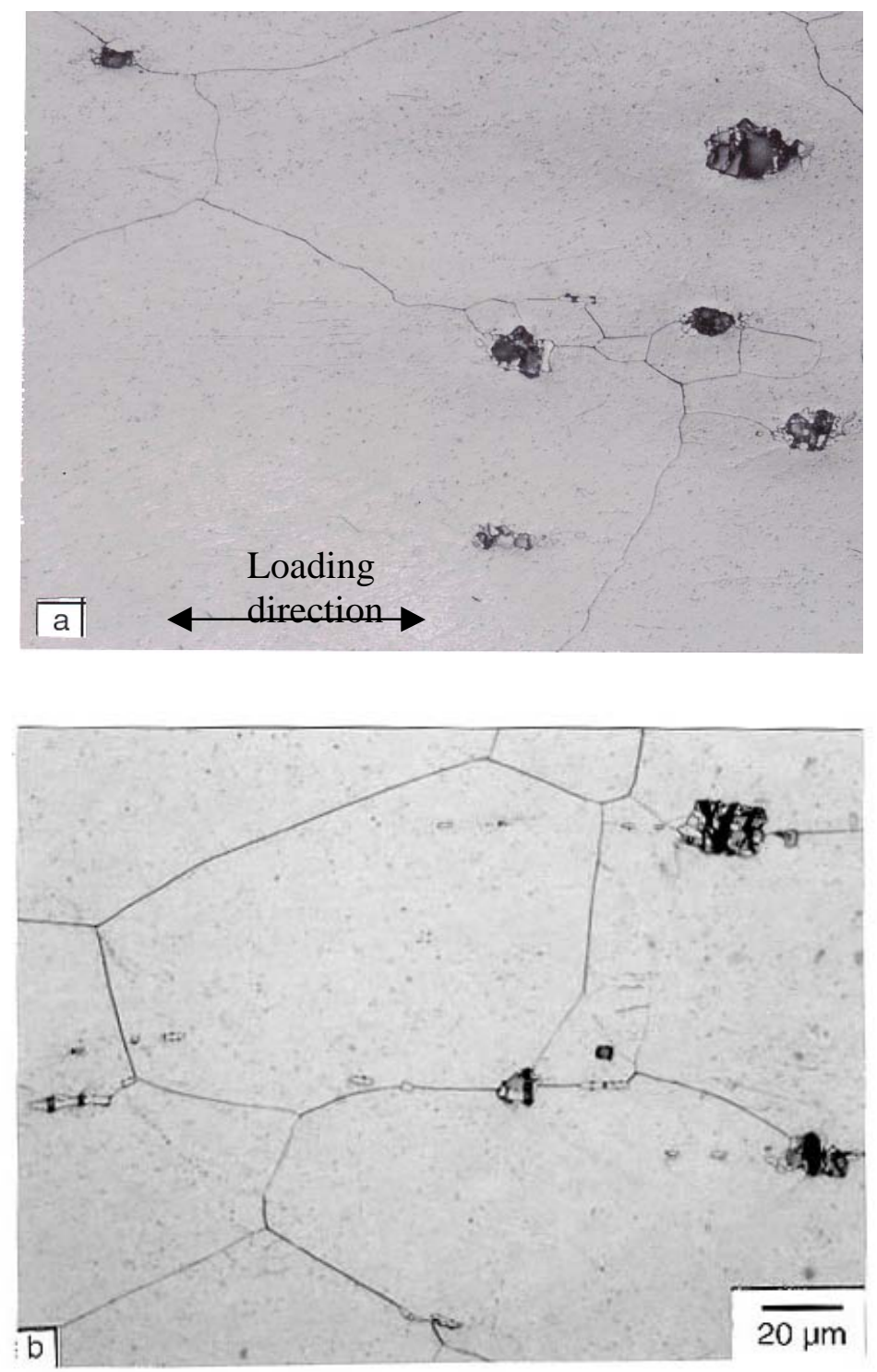

Figure 2. Void formation within inclusions of the tensile specimens strained to $25 \%$. 


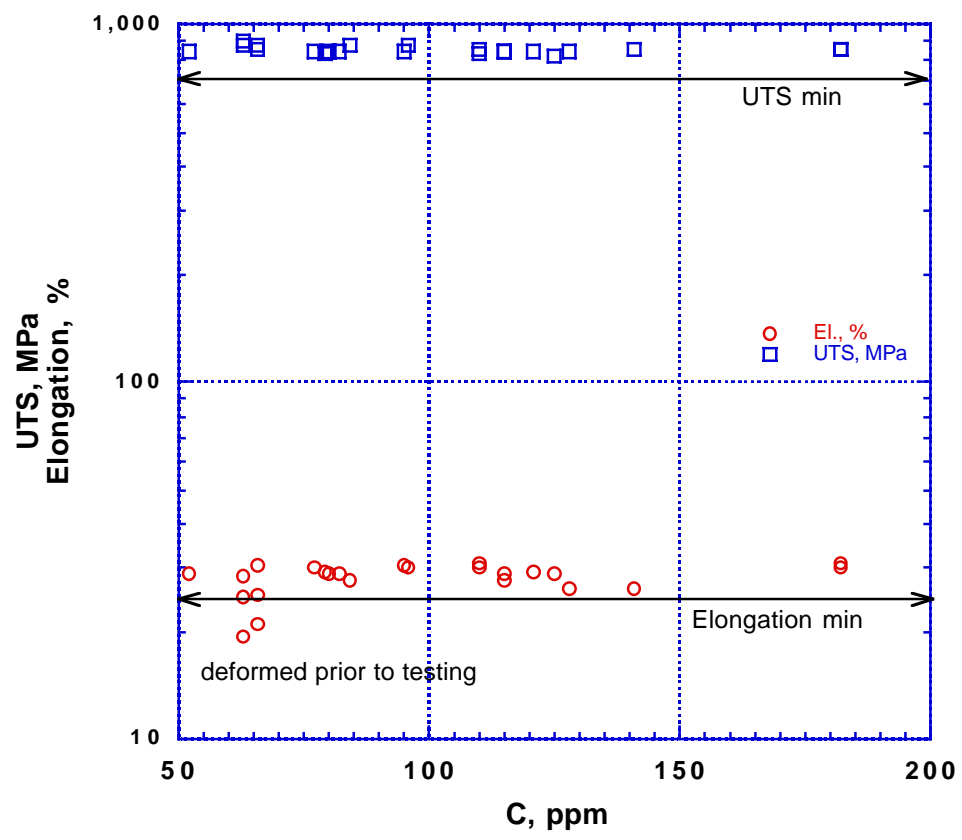

Figure 3. The effect of carbon content on the strength and ductility of the U-6Nb alloy. Deformed specimen data is from Ludwig [2]. 


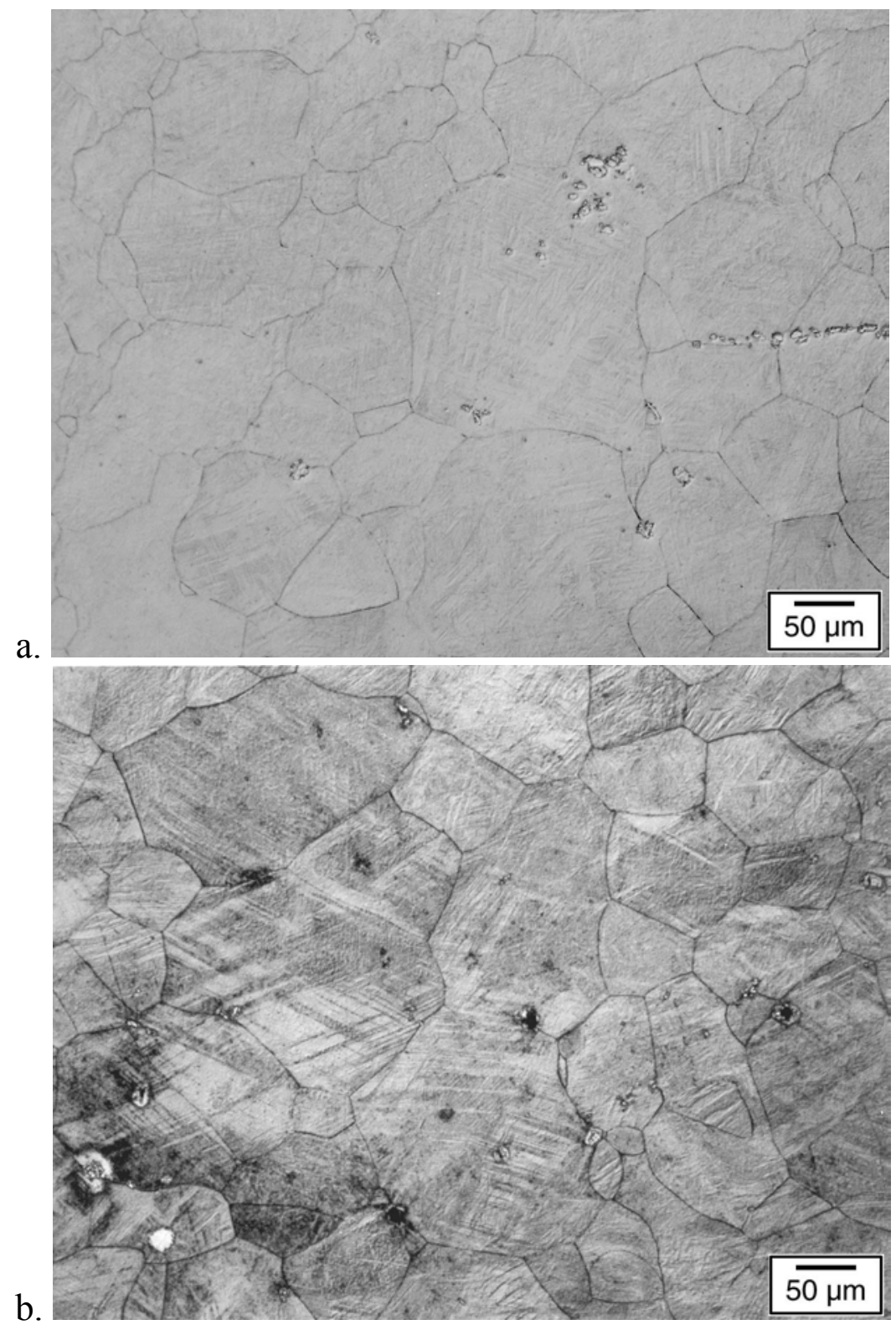

Figure 4, Microstructure of U-6Nb alloy emphasizing different features; a) the grain structure and inclusions and b) the presence of finely dispersed $\alpha$ " twin structure. 


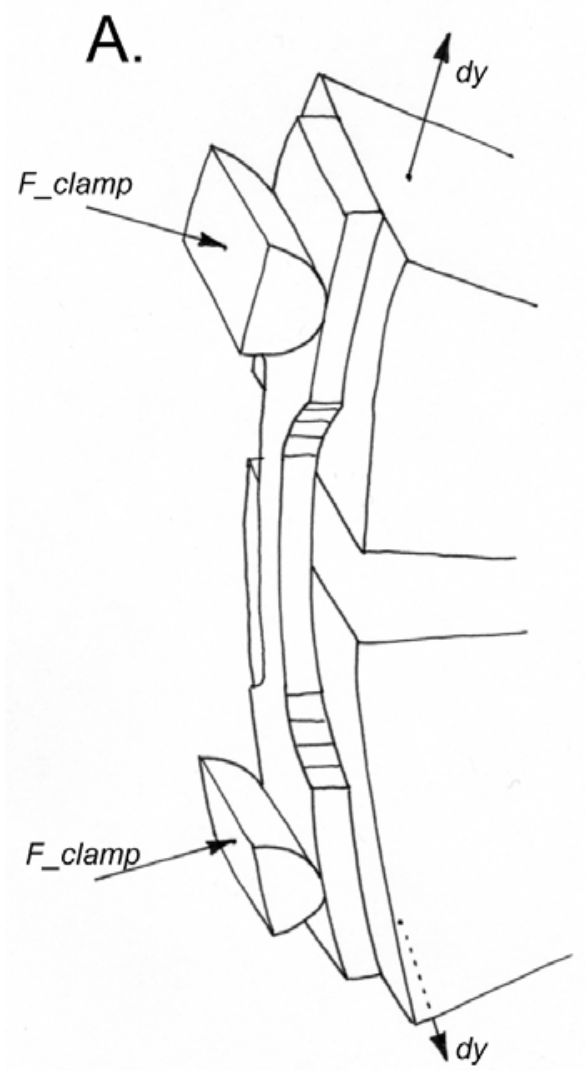

B.

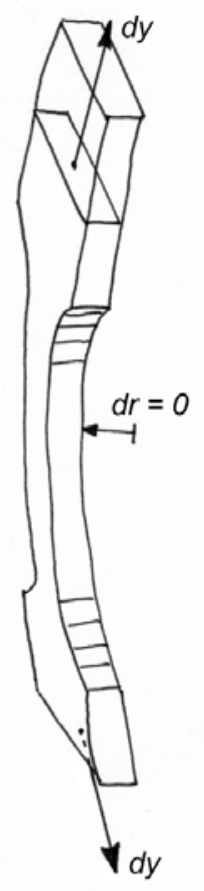

Figure 5. Schematics of actual condition a) and FEA boundary condition b). See Figure 1c for the test apparatus. 


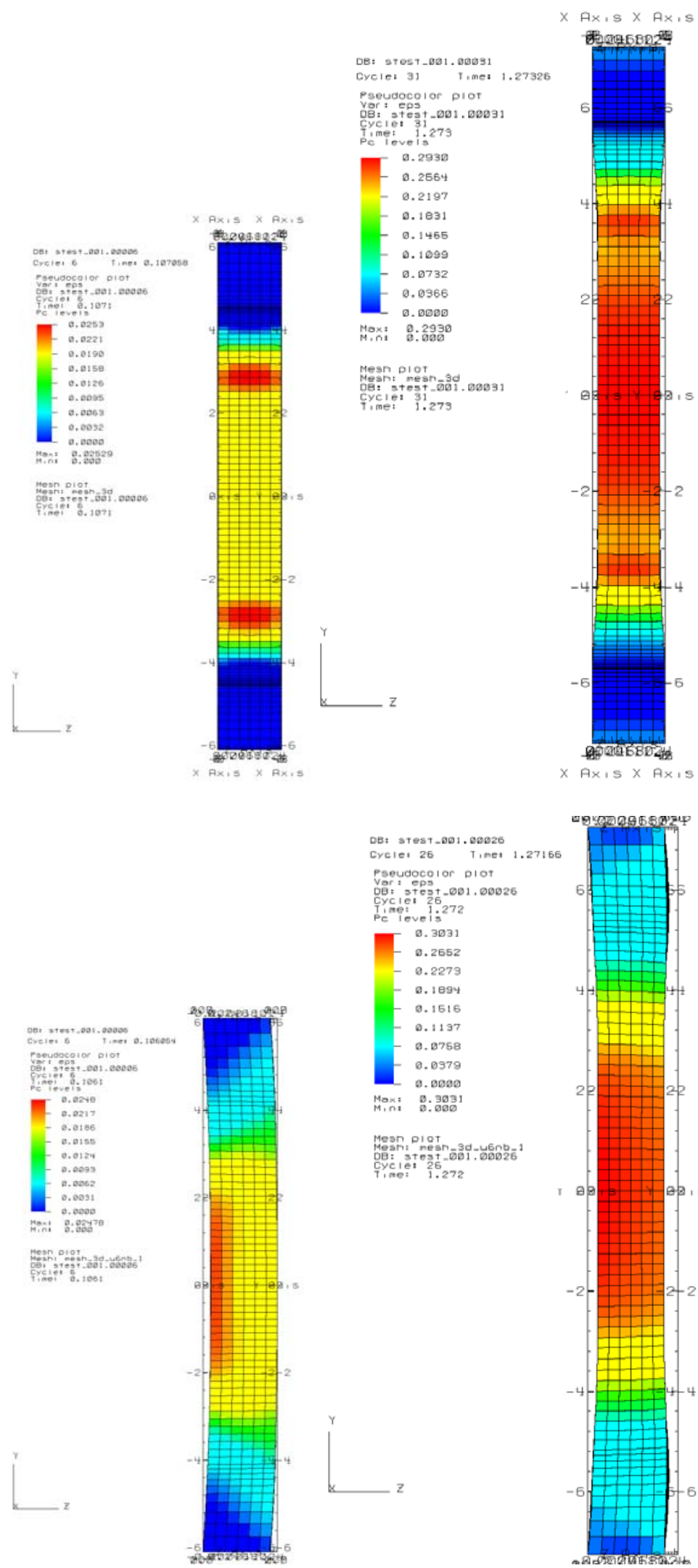

Figure 6. Initial and final equivalent plastic strain fringe plots for strainght and curved specimens (side view). 


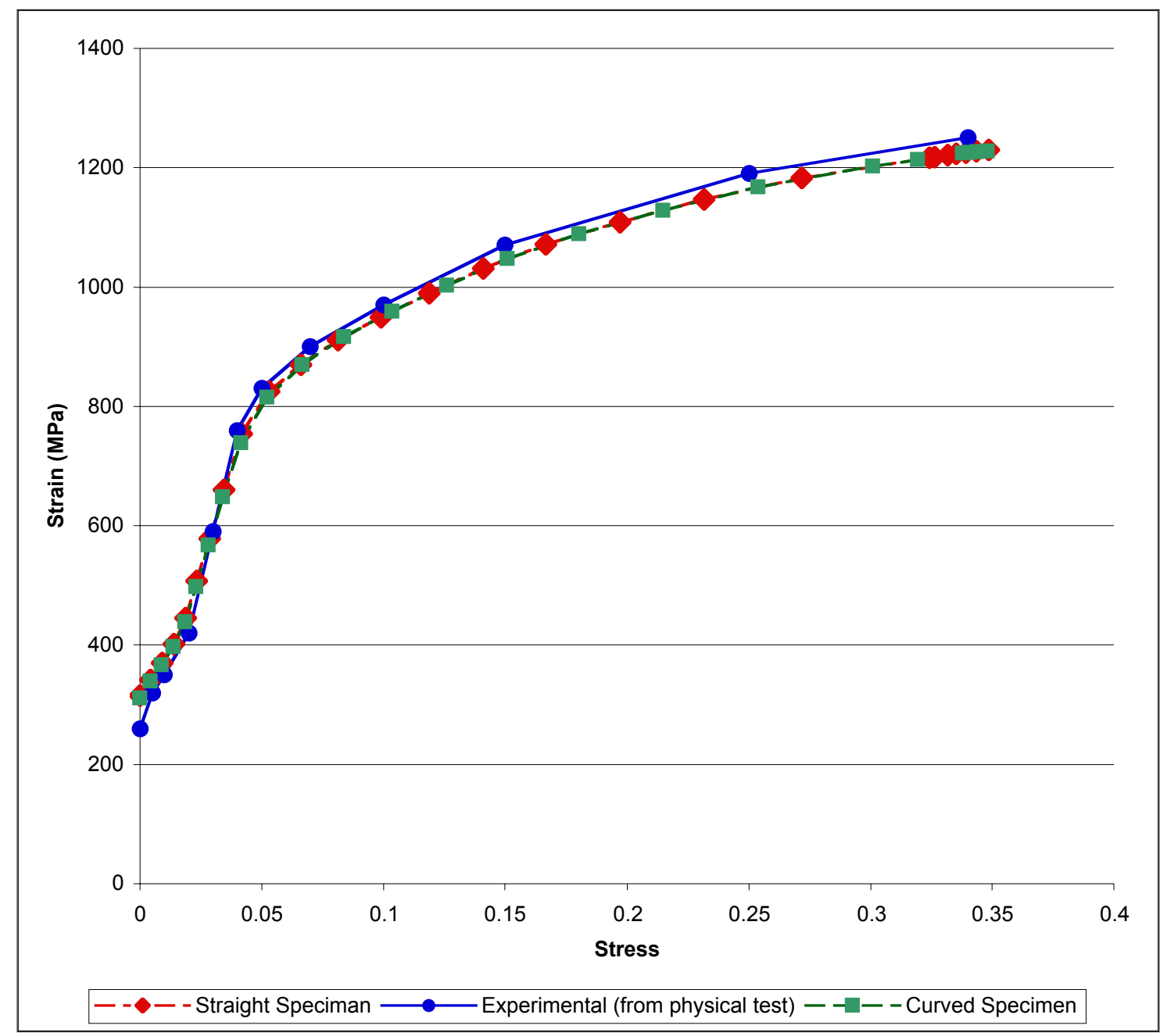

Figure 7. Stress-strain simulation output curves compared to the original experimental input curve. Note that the straight and curved specimen curves are from the FEA models. 

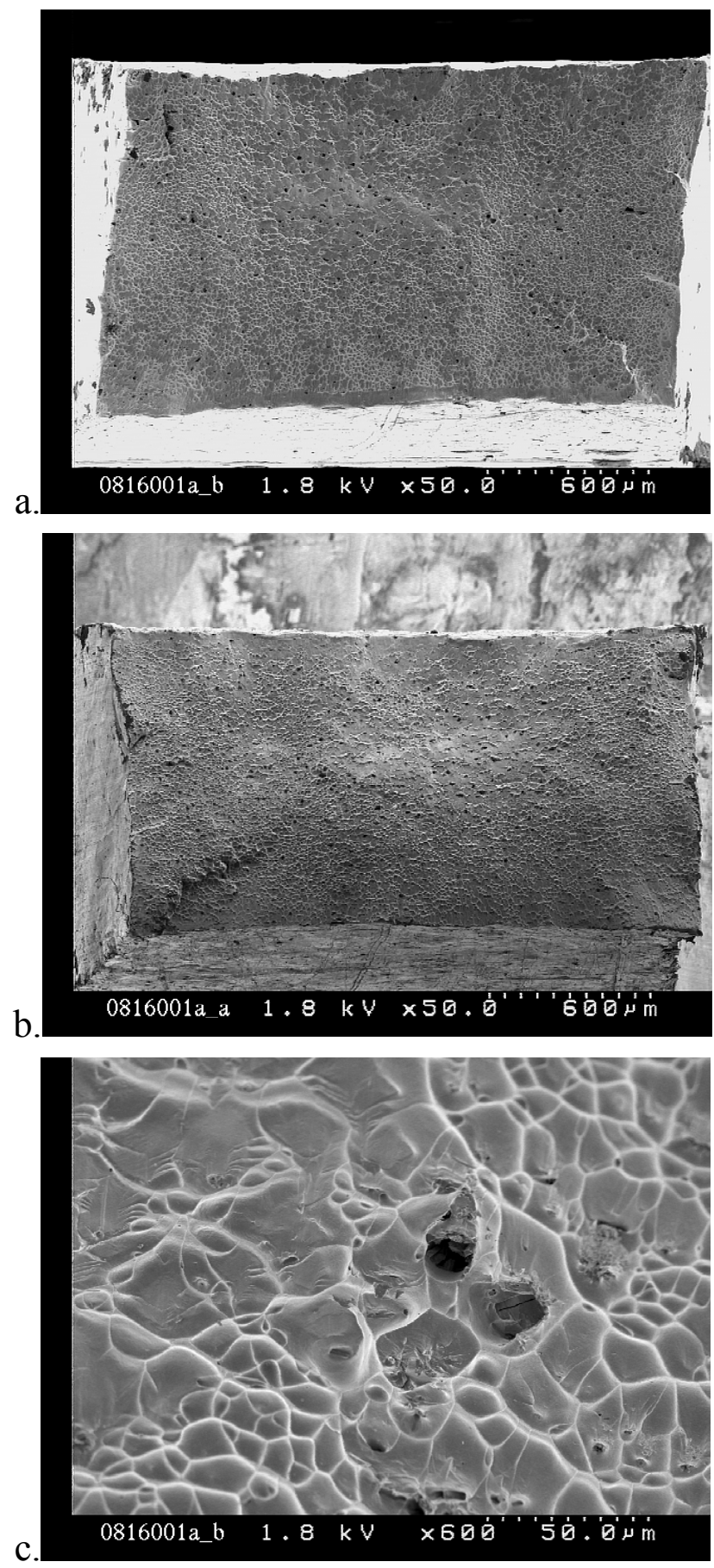

Figure 8. Fracture surfaces of broken WQU-6Nb alloy specimen that was naturally aged for 20 years: a) \& b) are the mating surfaces and c) is a higher magnfication view of a). 


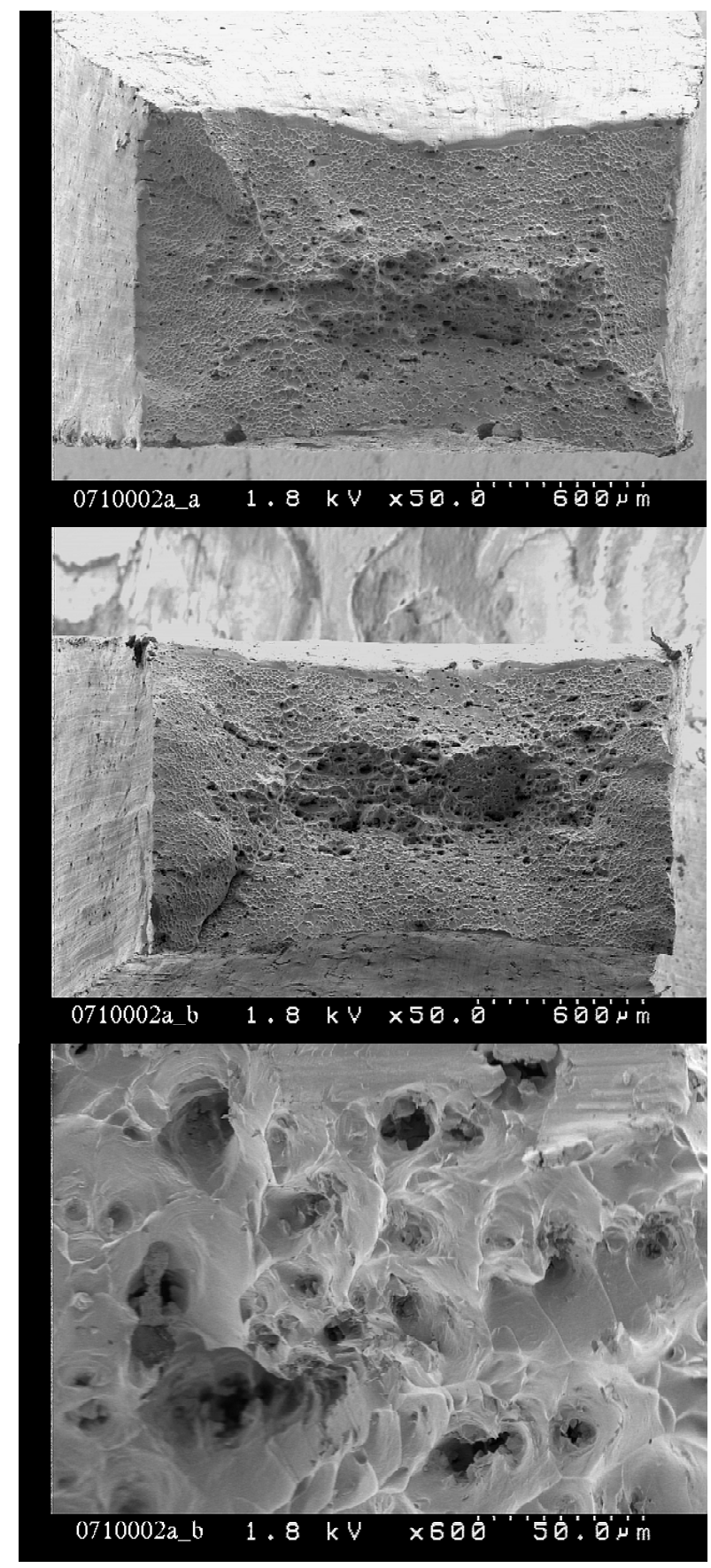

Figure 9. Fracture surfaces of broken AA U-6Nb alloy specimen that was naturally aged for 10 years: a) \& b) are the mating surfaces and (c) is a higher magnfication view from b) showing highly ductile microvoid coalescence fracture [20]. 